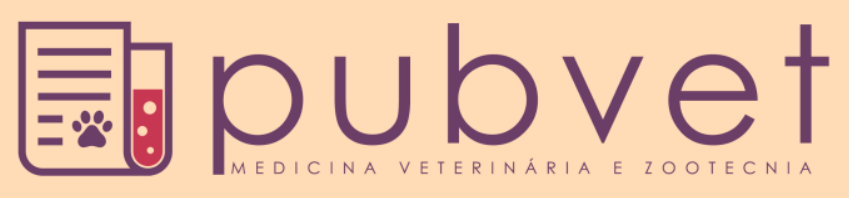

https://doi.org/10.22256/pubvet.v12n4a61.1-9

\title{
$O$ adestramento positivo como tratamento em cães com distúrbios comportamentais de ansiedade: Relato de casos
}

\author{
Virna Lívia Vieira Linhares ${ }^{*}$, Michelle Costa e Silva ${ }^{\bullet}$, Aline Maia Silva ${ }^{\bullet}$, Diana \\ Romão Bezerra 94
}

${ }^{I}$ Graduanda em Medicina Veterinária pela Faculdade Terra Nordeste - FATENE - E-mail: virnaahh@hotmail.com ${ }^{2}$ Professora Mestre da Faculdade Terra Nordeste (Caucaia, Ceará e Brasil) - E-mail: michelle.silva@fatene.edu.br ${ }^{3}$ Professora Doutora da Faculdade Terra Nordeste (Caucaia, Ceará e Brasil) - E-mail: aline.maia@ fatene.edu.br

${ }^{4}$ Pós-Graduanda em Clínica Médica e Acupuntura Veterinária e Mestre em ciências veterinárias-E-mail: dianaromao@gmail.com *Autor para correspondência

\begin{abstract}
RESUMO A interação entre as espécies humana e canina apresenta-se cada vez mais crescente e nela observa-se uma forte vinculação entre ambas as espécies. Essa relação, além de trazer benefícios, pode também trazer malefícios e prejudicar o bem-estar animal. Os problemas comportamentais são causados por uma série de fatores cuja raiz encontrase nas interações com o tutor e falta de conhecimento acerca da espécie canina e suas necessidades, que afetam diretamente a qualidade de vida do animal e fragilizam a relação homem-cão. Neste sentido, o presente estudo tem por objetivo perceber o adestramento positivo em cães para além dos comandos básicos, compreendendo-o como uma forma de conscientização e educação da família acerca das reais necessidades da espécie canina, promovendo o bem-estar, tornando-se uma maneira efetiva no tratamento de distúrbios comportamentais de ansiedade. Na metodologia foram utilizadas avaliações comportamentais e técnicas de adestramento positivo de forma sistemática, juntamente da tríade família-animal-ambiente, visando diminuir e modificar os comportamentos indesejados dos animais. Os resultados foram positivos, posto que os animais responderam bem aos exercícios propostos, sendo a maior dificuldade o engajamento do tutor na terapia comportamental, bem como o comprometimento na responsabilidade da educação animal diária; nota-se que o proprietário representa tanto o elemento provocador do problema quanto o agente terapêutico. Pode-se concluir com este trabalho que o adestramento positivo em cães é bastante eficaz no tratamento de distúrbios comportamentais de ansiedade, por promover o bem-estar, uma relação saudável dos animais com seus tutores, com o ambiente que os cercam e a interação com outras pessoas e animais. Por ser um tratamento comportamental é necessário tempo de execução para a obtenção de resultados duradouros. No entanto, são necessárias a conscientização e educação também da família com relação ao respeito dos comportamentos caninos, suas necessidades, temperamentos, a fim de que não haja nas relações a presença de estresse que possa desencadear os distúrbios de ansiedade.
\end{abstract}

Palavras chave: adestramento, comportamento animal, relação homem animal

\section{Use of positive training as treatment in dogs with behavioral anxiety disorders: Cases report}

ABSTRACT. The interaction between the human and canine species is increasingly increasing and there is a strong link between both species. This relationship, in addition to bringing benefits, can also bring harm and harm animal welfare. Behavioral problems are caused by a series of factors whose roots lie in interactions with the guardian and lack of 
knowledge about the canine species and their needs, which directly affect the animal's quality of life and weaken the man-dog relationship. In this sense, the objective of this study is to understand positive dog training in addition to the basic commands, understanding it as a way of raising awareness and education of the family about the real needs of the canine species, promoting well-being, an effective way to treat behavioral anxiety disorders. In the methodology, behavioral assessments and positive training techniques were used systematically, together with the family-animal-environment triad, in order to reduce and modify the negative behaviors of the animals. The results were positive, since the animals responded well to the proposed exercises, with the greatest difficulty being the engagement of the tutor in behavioral therapy, as well as the commitment on the responsibility of daily animal education; it is noted that the owner represents both the triggering element of the problem and the therapeutic agent. It can be concluded from this work that positive dog training is quite effective in the treatment of behavioral anxiety disorders, for promoting well-being, the best healthy relationship of animals with their guardians, the environment that surrounds them and the interaction with other people and animals. Because it is a behavioral treatment, execution time is necessary to obtain lasting results. However, the family's awareness and education regarding respect for canine behaviors, their needs and temperaments is also necessary so that there is no stress in the relationship that can trigger anxiety disorders.

Keywords: Training dog, behaviour animal, interaction human animal

\section{Utilización del adestramiento positivo como tratamiento en perros con disturbios comportamentales de ansiedad: Reporte de casos}

RESUMEN. La interacción entre las especies humana y canina se presenta cada vez más creciente y en ella se observa una fuerte vinculación entre ambas especies. Esta relación, además de traer beneficios, puede también traer maleficios y perjudicar el bienestar animal. Los problemas conductuales son causados por una serie de factores cuya raíz se encuentra en las interacciones con el tutor y falta de conocimiento acerca de la especie canina y sus necesidades, que afectan directamente la calidad de vida del animal y fragilizan la relación hombre-perro. En este sentido, el presente estudio tiene por objetivo percibir el adiestramiento positivo en perros más allá de los comandos básicos, comprendiéndolo como una forma de concientización y educación de la familia acerca de las reales necesidades de la especie canina, promoviendo el bienestar, haciéndose una manera efectiva en el tratamiento de los trastornos conductuales de ansiedad. En la metodología se utilizaron evaluaciones comportamentales y técnicas de adiestramiento positivo de forma sistemática, junto a la tríada familia-animal-ambiente, con el fin de disminuir y modificar los comportamientos no deseados de los animales. Los resultados fueron positivos, puesto que los animales respondieron bien a los ejercicios propuestos, siendo la mayor dificultad el compromiso del tutor en la terapia conductual, así como el compromiso en la responsabilidad de la educación animal diaria; se observa que el propietario representa tanto el elemento provocador del problema como el agente terapéutico. Se puede concluir con este trabajo que el adiestramiento positivo en perros es bastante eficaz en el tratamiento de trastornos conductuales de ansiedad, por promover el bienestar, una relación saludable de los animales con sus tutores, con el ambiente que los rodea y la interacción con otras personas y animales. Por ser un tratamiento conductual es necesario tiempo de ejecución para la obtención de resultados duraderos. Sin embargo, son necesarias la concientización y educación también de la familia con relación al respeto de los comportamientos caninos, sus necesidades, temperamentos, a fin de que no haya en las relaciones la presencia de estrés que pueda desencadenar los disturbios de ansiedad.

Palabras clave: adestramiento, comportamiento animal, relación hombre-perro 


\section{Introdução}

Historicamente, o cão é o animal doméstico que mais se associou ao homem ao longo dos anos. Acredita-se que esta relação tenha surgido a aproximadamente 15.000 anos atrás ((Thalmann et al., 2013).

Os lobos cinzentos (Canis lupus), antecessores primitivos dos cães foram animais responsáveis por uma importante reserva genética, a qual manifesta aproximadamente 90 padrões de comportamento entre si, garantindo características que os tornaram excelentes candidatos à seleção natural (Beaver, 2001, Horowitz, 2010).

Durante essa jornada evolutiva, as relações foram se estreitando, principalmente com aqueles animais que não tinham tanto potencial para a caça e acabavam se aproximando dos assentamentos humanos para se alimentarem de restos de comida despejados nas proximidades. A partir disto, os lobos mais calmos e menos temeroso ao convívio foram escolhidos para viver em sociedade dando início ao processo de domesticação. Ao longo das gerações, ocorreram cruzas seletivas que intensificaram aquelas características mais desejadas e tornaram outras secundárias, resultando em uma espécie com alterações morfológicas, fisiológicas e comportamentais até chegar aos padrões de raças que temos atualmente (Beaver, 2001, Horowitz, 2010).

Os cães exercem muitas funções além das quais ele exercia antigamente, sendo vistos como símbolos de status, membros da família, companhia, cães de resgate e polícia, assistência a deficientes físicos e pessoas com necessidades especiais, podendo também contribuir como terapeutas, assumindo grande importância na saúde mental e física das pessoas, visto que a sociedade moderna tende a isolar os seres humanos uns dos outros, com populações cada vez mais solitárias (Tatibana \& Costa-Val, 2009).

O interesse científico nas relações e interações entre pessoas e animais de estimação tem uma tradição estabelecida há muito tempo e foi institucionalizada no mundo social de Ciência. Atualmente uma série de periódicos psicológicos, sociológicos, antropológicos em todo o mundo se propõem a estudar diferentes aspectos deste assunto (Konecki, 2007). Isso porque a relação do homem com os animais promove um vínculo que estimula mudanças positivas no comportamento das pessoas influenciando melhorias no convívio social, diminuição de distúrbios psicológicos com redução da ansiedade, além de significativas respostas contra doenças, contribuindo para a felicidade do ser humano (Herzog, 2011).

O Brasil é o $4^{\circ}$ país do mundo em população total de animais de estimação com um total de 52,5 milhões de cães e 22,1 milhões de gatos, fomentando a ideia de um novo modelo familiar, a família multi-espécie, com novos arranjos sociais, proporcionando um ambiente mais propício ao surgimento desse vínculo (Faraco \& Seminotti, 2004). As relações dos animais dentro das famílias atualmente estão sofrendo uma modificação. Estão cada vez menores. É crescente o número de pessoas morando sozinhas e com isso o sentimento e maior apego aos pets é intensificado (Hannah \& Robertson, 2017).

Entretanto, conviver de perto com o cachorro pode causar sentimentos intensificados, hiper apego e um risco de humanização exagerada por parte do tutor, desencadeando interpretações acerca do comportamento do animal, onde o proprietário não enxerga o cão como sendo de uma espécie diferente da humana, nos fazendo acreditar que os animais pensam e sentem como nós, criando expectativas enganosas e deixando de suprir suas necessidades básicas (Tatibana \& Costa-Val, 2009, Horowitz, 2010). De acordo com Gerger \& Rossi (2011) a humanização fragiliza a relação, pode causar sofrimento ao animal, deficiências na comunicação e colocar em risco o bem-estar do mesmo.

Ter um cão requer compromisso, disciplina e organização, pois os cães são animais sociáveis que em geral não toleram ficar sem companhia mais que 6 horas por dia, necessitam de estímulos mentais e atividades físicas diárias e precisam ser educados e socializados desde filhotes. Condutas que devem ser avaliadas antes de adquirir o animal, na garantia de que isso existirá na prática (Gerger \& Rossi, 2011).

Os cães interpretam o mundo de uma maneira completamente diferente dos seres humanos, tem valores e necessidades distintas e não pensam da mesma forma (Tatibana \& Costa-Val, 2009). Fazem contato visual para obter informações, nossas emoções, o que está acontecendo e observam tudo para poderem se orientar (Horowitz, 2010). As pessoas não têm noção disso, a menos que tenham estudado sobre comportamento animal ou psicologia. Os proprietários atingem um ponto de estarem diante de comportamentos complexos, reações e habilidades que não sejam capazes de lidar 
(Broom, 1991). De acordo com Gerger \& Rossi (2011) as reações que os tutores tomam frente aos comportamentos apresentados pelo animal são extremamente relevantes, podendo reforçar ou extinguir ações, afetando a qualidade de vida de ambos e o grau de satisfação do proprietário em relação ao cão.

O cotidiano nas sociedades atuais faz com que os cachorros estejam cada vez mais dentro de apartamentos, em ambientes restritos e sozinhos, muito diferente do natural, o animal não consegue expressar seus comportamentos de espécie (Crossman, 2017). Por isso avaliar a conduta dos tutores frente às necessidades básicas da espécie canina, a capacidade de se comunicar da maneira correta e o conhecimento da espécie no geral, pode ser uma maneira de se avaliar o bem-estar e a qualidade de vida do animal (Ferreira \& Sampaio, 2010).

\section{$\mathrm{O}$ isolamento pode resultar em comportamentos destrutivos, inatividade, ansiedade ou comportamentos estereotipados, como correr atrás do próprio rabo, caça a sombras ou insetos imaginários repetidas vezes e lambedura excessiva podendo ocorrer automutilação no flanco ou nas patas, comprometendo o estado físico, mental e emocional apresentando sintomas comparados aos sentimentos humanos de depressão, dependendo do indivíduo e de cada contexto (Beaver, 2001, Rooney et al., 2009, Broom, 1991).}

Segundo Gerger \& Rossi (2011) a grande maioria dos problemas comportamentais nos animais de companhia acontece em decorrência de uma série de fatores a partir do estresse de um ambiente sem estímulos, espaços inadequados, socialização pobre, relação de dependência, castigos incorretos, hiperatividade mal direcionada e dificuldade de comunicação entre tutor e animal.

Uma série de sintomas podem ser observados; se esconder, orelhas para trás, andar de um lado para o outro, eliminação inadequada, arfar, babar, vocalização excessiva. A ansiedade, medos e fobias estão entre os distúrbios comportamentais mais comuns nos cães, incluindo alterações como ansiedade generalizada, ansiedade de separação e fobias a estímulos como trovoadas, fogos de artifício e outros barulhos (Gruen \& Sherman, 2008).

Identificar o tipo de ansiedade que o cão sofre, as possíveis causas e o que desencadeia é essencial para encontrar um plano de tratamento adequado, além de descartar eventuais condições médicas que estejam causando os sintomas. Muitas vezes, estes distúrbios comportamentais são causados por uma variedade de fatores, sendo a melhor maneira de tratá-los através de uma combinação de treinamentos, estratégias preventivas e, em alguns casos, medicamentos (Sargisson, 2014), assim como terapia naturais como a homeopatia e florais de Bach (Horowitz, 2010, Landsberg et al., 2013).

Entre as diversas técnicas de adestramento e modelagem comportamental, as mais utilizadas nesses casos são o contra condicionamento e a dessensibilização sistemática. Com o contra condicionamento, tenta-se mudar a resposta negativa do animal a um determinado estímulo, por respostas mais agradáveis, substituindo o comportamento ansioso por outro desejável como sentar, por exemplo. A dessensibilização sistemática, consiste em expor o animal a um estímulo, em intensidades gradualmente crescentes, até que o animal deixe de reagir de maneira negativa a esse estímulo (Morgan \& Tromborg, 2007).

Além disso, o adestramento ajuda na comunicação entre tutor e cão, aumenta o acervo de comportamentos desejados e consequentemente, no conhecimento acerca da espécie canina e a interpretação correta dos comportamentos, tornando os cães mais sociáveis e interativos com o tutor e o mundo (Gerger \& Rossi, 2011).

Este artigo tem por objetivo perceber o adestramento positivo em cães para além de comandos básicos, mas como uma forma de tratamento de distúrbios comportamentais de ansiedade, a fim de promover o bem-estar, estabelecendo uma relação saudável entre tutor e animal através da conscientização e educação da família acerca das reais necessidades da espécie canina e como agir frente aos diversos comportamentos caninos. Por meio deste estudo pretende-se avaliar a hipótese de que o tutor não consegue muitas vezes perceber o ser complexo com o qual estão lidando, negligenciando necessidades e humanizando o animal a ponto de provocar distúrbios comportamentais dos quais eles não sabem lidar, chegando a pontos críticos de comportamento, gerando assim estresse que acaba por fragilizar a relação. 


\section{Material e Métodos}

Serão abordados neste trabalho dois casos de cães com distúrbio de ansiedade. O primeiro caso trata-se de um paciente da raça Bulldog Francês, fêmea, de 1 ano, pesando $10 \mathrm{~kg}$ que foi atendida no dia 22 de fevereiro de 2017, onde a queixa principal relatada pelo tutor era a agitação excessiva, a destruição dos objetos da casa como portas, paredes, armários, mesas e calçados, hiper apego a figura do dono, vocalização excessiva para barulhos, na chegada e saída do tutor e nos passeios. Esse comportamento de vocalização e agitação era triplicado ao andar de carro com o proprietário, inviabilizando completamente o passeio, $\mathrm{o}$ animal se agitava a tal ponto que chegou a quebrar o cinto de segurança no intuito de ficar no colo de seu tutor.

O ambiente social era composto pelo proprietário e sua mãe. A cadela era mantida em uma área próxima à cozinha, restrita, onde ficava a maior parte do tempo, com acesso ao restante da casa apenas sob supervisão e por curto período de tempo, saindo à rua esporadicamente para passeios curtos. A alimentação era ração comercial seca à vontade. $\mathrm{O}$ animal estava saudável, vacinado e vermifugado.

Foi realizada uma avaliação comportamental com observação do comportamento da cadela, das condições de criação do ambiente onde ela vive e da sua interação com os outros membros da família, a fim de entender o que está incomodando todos na casa. Além disso foi questionado o que o tutor espera da cadela, sua rotina, a relação da fêmea com outros animais e o comportamento desta em seu ambiente natural.

Todos esses questionamentos na primeira conversa com os tutores são essenciais para saber como toda a família se relaciona com o comportamento do cão e tudo que já foi feito na tentativa de melhorá-lo. O tratamento instituído foi a administração de florais de Bach manipulado para ansiedade diariamente na água e técnicas de adestramento positivo e modificação comportamental além de incluir na rotina da cadela passeios diários e a implementação de enriquecimento ambiental. $\mathrm{O}$ pedido de deixar o animal livre pela casa foi negado imediatamente pelo proprietário. Implementou-se a primeira técnica utilizada no intuito de controlar as vocalizações excessivas quando o tutor chegava ou se ausentava e quando recebia alguma visita. Em seguida foi instituído o contra condicionamento com reforço positivo com treinos sistemáticos que o tutor deveria praticar diariamente, como parte da rotina do animal.

O segundo caso a ser abordado é de duas pacientes caninas, sem raça definida, fêmeas, ambas de 2 anos e 3 meses que foram atendidas no dia 24 de outubro de 2017. A Tutora relatou que as cadelas apresentam esporadicamente micção inapropriada em colchões e destruição de objetos, vocalização para barulho externos, comportamento inquieto, vocalização e agitação com a chegada de pessoas, inclusive dos próprios tutores. Enfatizou que o comportamento que mais incomodava era as vocalizações excessivas e a agitação extrema nos passeios, onde as cadelas puxavam bastante a guia e demostravam agressividade com outros animais na rua, demonstrando ser uma atividade muito estressante para as cadelas. Uma das fêmeas tinha medo da guia, se escondia e não deixava colocar, a mesma também tinha o hábito de lamber as patas constantemente.

As cadelas residem em apartamento, onde têm livre acesso aos cômodos, não passeiam e uma vez por semana visitam a casa de praia da tutora, onde ficam soltas e à vontade. Possuem poucos brinquedos e não têm contato com outros animais. As cadelas são saudáveis, vacinadas, vermifugadas e alimentadas com ração seca comercial. O ambiente social é composto pelo casal de tutores, a secretária e uma idosa, a mãe da tutora.

A avaliação comportamental foi longa, com um apanhado sobre o histórico e a observação das cadelas, inicialmente dentro da residência, sua rotina, avaliação ambiental e a relação de ambas com seus tutores. Em seguida, a avaliação foi externa, onde analisou-se todo o comportamento das cadelas e dos tutores desde o momento de colocar as guias até a saída, o comportamento com outros animais e quais eram as reações e condutas dos tutores nas diversas situações.

Relatou-se que o proprietário perdia a paciência com as cadelas, tentava puni-las pelo comportamento e antes de colocar as guias já se demonstrava irritado, sendo o passeio algo estressante para todos do começo ao fim. Já a outra tutora tratava as cadelas como crianças, falando mansamente e sendo muito permissiva em diversos comportamentos.

Nesse caso também foi instituído o tratamento com o adestramento positivo e modelagem comportamental. 


\section{Resultados e Discussão}

$\mathrm{Na}$ primeira paciente pediu-se ao tutor para ignorar o comportamento da cadela até que ela estivesse calma e só assim o proprietário poderia dar atenção e carinhos. Os cães são capazes de aprenderem através de ações treinadas pelo homem, onde por meio de recompensas e punições é gerada uma predisposição à aceitação de comandos que os tornam mais sociáveis e receptivos, muitas vezes sendo capazes de imitar as ações humanas (Fugazza \& Miklósi, 2015). A cadela deveria ficar calma e se sentar para que abrissem o portão. O cão deve realizar uma ação voluntária de sentar e relaxar, gerando a recompensa de sair para o restante da casa. Caso ela não sente e relaxe, o portão não abre, gerando um tipo de punição para o animal, mostrando que o comportamento tem uma consequência. A esse sistema de recompensa e punição, damos o nome de condicionamento operante, que são influenciados pelas suas consequências. $\mathrm{O}$ condicionamento operante através de reforço positivo também foi utilizado como forma de ensinar comandos básicos como senta, deita e fica, no intuito de facilitar a terapia comportamental, em que a ferramenta utilizada foi o clicker, um pequeno aparelho de plástico que dentro possui uma lingueta de metal que ao ser pressionada emite um som e sinaliza o comportamento exato que será recompensado (Chiandetti et al., 2016). Em todos os comportamentos ansiosos da cadela em questão foi adotado o contra condicionamento, que consiste numa técnica de modificação comportamental usada tanto em humanos como animais que substitui um comportamento indesejado por outro desejável e agradável, onde os comportamentos ansiosos apresentados pelo animal foram substituídos por outros mais calmos.

A cadela ficava bastante ansiosa no portão que a liberava para o restante da casa, uivava, grunhia e se jogava no portão, demorando um tempo considerável para relaxar, o contra condicionamento criou o comportamento dela esperar sentada que alguém abrisse o portão e a liberasse. A técnica de dessensibilização sistemática foi adicionada quando fomos treinar o animal para passear de carro, a qual consiste em expor o animal ao estímulo causador da ansiedade, em pequenas doses e a uma distância que a cadela conseguisse se controlar. $\mathrm{O}$ enriquecimento ambiental visa incrementar o ambiente onde o animal vive, para que ele possa expressar condutas normais da espécie, equilibra seu sistema emocional, estimulando o físico e o mental, melhorando a aprendizagem e a capacidade de resolver problemas, minimizando o estresse se instituído de forma diária (Morgan \& Tromborg, 2007).

Após um mês, a paciente apresentou melhoras consideráveis na convivência com a família, se demonstrando mais calma e menos agitada dentro da residência, porém ainda apresentava comportamentos instáveis e ansiosos quando o tutor se ausentava mesmo que por poucos instantes e dentro do carro, oscilando entre melhoras e pioras, sendo muito difícil controlá-la nessas duas situações, onde o animal estava tão ansioso que não aceitava mais petiscos, arfava, babava e vocalizava muito, piorando consideravelmente se o treino se prolongasse. $\mathrm{O}$ tutor relatou ainda que a cadela se demonstrava mais instável com a sua presença do que com o adestrador. $\mathrm{O}$ adestramento é uma forma de relacionamento, que para ser mantido precisa de muita constância e dedicação. Somado a isso, a falta de conhecimento sobre a linguagem comunicativa do cão e a forma como o tutor reage as situações influencia o cão a reagir da mesma forma, o que pode ser bom ou mau, criando e reforçando comportamentos que não são desejáveis na relação (Gerger \& Rossi, 2011). O cão adestrado respeita mais a relação hierárquica e se mostra mais obediente frente ao adestrador, enquanto o tutor demonstra atitudes que são frequentemente complexas, inconsistentes, de alta carga emocional e dependente da personalidade de cada um (Raileanu \& Teixeira, 2015).

A terapia comportamental não foi instituída por completo nesse primeiro caso, pois o proprietário relatou ter dificuldades para treinar com o animal devido à falta de tempo e não tinha uma rotina, a cadela se mantinha restrita ainda no mesmo ambiente e sem enriquecimento ambiental. Para os passeios, foi contratada uma terceira pessoa, tornando os passeios diários, duas vezes por dia, porém as instruções de controle da ansiedade da terapia comportamental não foram seguidas e a cadela não evoluiu em socialização com outros animais.

A mãe do tutor se isentou de interagir com o animal e não seguia nenhuma instrução da terapia. Já o tutor passava mais de 8 horas longe de casa e era a única figura da família que interagia, brincava e soltava o animal para o restante da casa. Para que o animal não passasse muito tempo em um ambiente restrito foi sugerido o serviço de Creche Canina - Day Care, onde o animal teria a 
oportunidade de socializar e gastar energias acumuladas, pedido este que foi negado. Sendo os cães animais sociais, o contato com outros da mesma espécie e com pessoas é uma necessidade comportamental. A privação estimula a ansiedade e os comportamentos destrutivos, influenciando no estado físico, mental e emocional do animal (Rooney et al., 2009). Frequentar creches algumas vezes por semana pode fazer uma grande diferença na relação tutor animal.

Foi instituído então, que a cadela não parasse com os passeios diários, nem com os exercícios de controle da ansiedade por parte do tutor, continuasse com o floral por até 3 meses, pois são produtos naturais, que não possuem toxicidade $\mathrm{e}$ nem efeitos colaterais e são de grande utilidade, com um efeito mais rápido nos animais do que nos humanos e ajudam a reequilibrar os estados mentais e emocionais do animal (Landsberg et al., 2013). Foi reforçada ainda a necessidade de introduzir o enriquecimento ambiental na rotina da cadela, de forma a minimizar o estresse do animal. Estudos indicam que um ambiente enriquecido estimula o físico e o mental, melhoram a aprendizagem e a capacidade de resolver problemas, além de incentivar a manifestação do comportamento natural e melhorar o bem-estar, visto que o comportamento dos cães também é influenciado pelas condições do ambiente onde vivem (Morgan \& Tromborg, 2007).

Em outubro de 2017, houve um novo contato com o tutor, onde relatou que havia suspendido o floral no mesmo dia do fim da terapia comportamental, que o animal ainda passava a maior parte do tempo restrito, sem a atenção devida e sem enriquecimento ambiental, voltando a apresentar comportamentos ansiosos dentro da residência, comportamentos estes que haviam cessado com o adestramento positivo como as destruições, vocalizações e os descontroles para colocar a guia de passeio, reforçando a ideia de Ferreira \& Sampaio (2010) de que é muito importante avaliar as condutas dos tutores frente às necessidade básicas da espécie como uma maneira de se avaliar o bem-estar e a qualidade de vida do animal, sendo o comportamento um indicativo expressivo de alto ou baixo grau de satisfação com a vida.

Quanto ao segundo caso inicialmente, devido a ansiedade das cadelas, os treinos se limitaram à residência, com dessensibilização em relação à guia em uma das cadelas, que sentia desconforto e fugia da ferramenta de passeio. A Sensibilidade ao
Processamento Sensorial (SPS) analisa até que ponto os animais compartilham dimensões de personalidade equivalentes às encontradas em seres humanos e pode influenciar a forma como as pessoas percebem o meio ambiente e como isso os afeta, semelhante ocorre com os animais diante de uma situação que os desconforta (Braem et al., 2017). O contra condicionamento também foi adicionado com as guias, pois só o ato de chegar perto do local onde as guias estavam guardadas já estimulava o comportamento ansioso. Ao colocar as guias, o comportamento ansioso piorava e as cadelas apresentavam diversos sinais como: vocalização, andar de um lado para o outro, se sacudir, passar a língua nos lábios, bocejar, arfar, e babar e uma das duas não aceitava petisco quando nesse estado, ambas demoravam mais de 30 minutos para demonstrar diminuição do comportamento ansioso.

No primeiro treino externo, com a ansiedade já controlada desde a residência, as cadelas não exibiram comportamentos de vocalização, porém puxavam bastante a guia. Não foram liberadas para passear na rua, se limitando apenas ao estacionamento, até que demonstrassem comportamentos menos ansiosos. Ao encontrar com outro cão, também não latiram, mas ficaram bastante agitadas. Ao serem liberadas para passear na rua, mantiveram o comportamento mais calmo, se mantendo mais tempo sem puxar a guia, mais tranquilas e sem vocalização ou agressividade quando avistavam outros animais. $\mathrm{O}$ enriquecimento ambiental diário também foi adicionado ao tratamento. As cadelas passavam a maior parte do dia sem atividade alguma, dormindo a maior parte do tempo. Um ambiente enriquecido com diversos estímulos proporciona atividades para o animal tirando-o do ócio e controlando seu ambiente, equilibrando seu sistema emocional, ajudando-o na adaptação, contribuindo para que ele possa apresentar condutas normais (Morgan \& Tromborg, 2007). As cadelas, até o dado momento, se encontram na sua sexta aula e os tutores e amigos próximos já notam sinais de tranquilidade nos animais e se demonstram satisfeitos com os resultados obtidos. As vocalizações não existem mais em nenhuma das situações mencionadas, a cadela que sentia desconforto com a guia, está mais tranquila e cedendo mais rápido ao estímulo. Porém, somente um dos proprietários apresentava disponibilidade para passear com as cadelas, tendo dificuldade para participar das aulas, devido a rotina intensa de trabalho, mas se esforçava para seguir com a 
terapia comportamental. O enriquecimento até o dado então momento não havia sido implementado.

Em ambos os casos, independentemente do desfecho, a grande dificuldade foi convencer os proprietários a se engajarem na terapia comportamental proposta. No tratamento de distúrbios comportamentais, a base da terapia é o proprietário, o que torna o elemento provocador do problema em agente terapêutico. Os tutores depositam toda a melhora do animal no adestrador e muitas vezes se ausentam das responsabilidades para com o animal (Chung et al., 2016). No $2^{\circ}$ caso foi visível o papel desencadeador que o proprietário tinha, porém, a partir da implementação da terapia comportamental, que na realidade implica numa modificação da relação cão dono, a melhora do comportamento foi acentuada. Além disso, o animal passa a ser encarado como uma fonte de prazer e não apenas como um problema, realçando o papel lúdico do animal de companhia através de brincadeiras e passeios, onde, embora não tenha se extinguido alguns comportamentos por completo, os proprietários já estavam plenamente satisfeitos com o resultado do tratamento. Já no caso 1, não foi possível implementar a terapia comportamental de maneira eficiente, o que pode explicar o insucesso do tratamento. Não havendo mudança no ambiente físico e social, fica muito difícil modificar o comportamento. Como fatores agravantes no $1^{\circ}$ caso temos a restrição física; o isolamento social e o fato de que o animal só tinha relações apenas com um membro da família, desenvolvendo um hiper apego pelo tutor, pois este era o responsável por trazer-lhe bem-estar, piorando os comportamentos ansiosos na presença do mesmo. $\mathrm{O}$ uso do floral pareceu ser benéfico no caso, contudo são necessários mais estudos controlados.

Com base na metodologia utilizada e nos resultados obtidos, pode-se constatar de forma prática que a conduta das pessoas tem influência direta no comportamento do cão e que consequentemente reflete na própria satisfação do tutor. Um cão que não realiza atividades físicas, mentais e sociais pode manifestar problemas comportamentais diversos, sendo o ambiente onde vive um fato de extrema importância na qualidade de vida do animal. As condutas psicológicas inadequadas do tutor, a falta de conhecimento, empatia e responsabilidade pelo bem-estar do animal pode gerar interações pouco saudáveis entre eles, levando a uma má qualidade na vida de ambos. É necessário conscientizar as pessoas acerca das reais necessidades caninas e salientar a importância do enriquecimento ambiental e da socialização, pois atualmente, o número de animais domiciliados é muito grande, porém animais cada vez mais restritos e solitários, completamente sem atividades, aumentando consideravelmente o número de distúrbios comportamentais e comportamentos cada vez mais ansiosos.

\section{Conclusão}

O adestramento positivo em cães é bastante eficaz no tratamento de distúrbios comportamentais de ansiedade, por promover o bem-estar, uma relação saudável dos animais com seus tutores, com o ambiente que os cercam e a interação com outras pessoas e animais. Por ser um tratamento comportamental é necessário tempo de execução para a obtenção de resultados duradouros. No entanto, são necessárias a conscientização e educação também da família com relação ao respeito dos comportamentos caninos, suas necessidades, temperamentos, a fim de que não haja nas relações a presença de estresse que possa desencadear os distúrbios de ansiedade.

\section{Referências Bibliográficas}

Beaver, B. V. 2001. Comportamento canino: um guia para veterinários. Roca, São Paulo, Brasil.

Braem, M., Asher, L., Furrer, S., Lechner, I., Würbel, H. \& Melotti, L. 2017. Development of the "Highly Sensitive Dog" questionnaire to evaluate the personality dimension "Sensory Processing Sensitivity" in dogs. PloS one, 12, e0177616.

Broom, D. M. 1991. Animal welfare: concepts and measurement. Journal of Animal Science, 69, 4167-4175.

Chiandetti, C., Avella, S., Fongaro, E. \& Cerri, F. 2016. Can clicker training facilitate conditioning in dogs? Applied Animal Behaviour Science, 184, 109-116.

Chung, T.-h., Park, C., Kwon, Y.-m. \& Yeon, S.c. 2016. Prevalence of canine behavior problems related to dog-human relationship in South Korea-A pilot study. Journal of Veterinary Behavior: Clinical Applications and Research, 11, 26-30.

Crossman, M. K. 2017. Effects of interactions with animals on human psychological distress. Journal of Clinical Psychology, 73, 761-784. 
Faraco, C. B. \& Seminotti, N. 2004. A relação homem-animal e a prática veterinária. Revista CFMV , 10, 57-62.

Ferreira, S. A. \& Sampaio, I. B. M. 2010. Relação homem-animal e bem-estar do cão domiciliado. Archives of Veterinary Science, 15, 22-35.

Fugazza, C. \& Miklósi, Á. 2015. Social learning in dog training: The effectiveness of the Do as I do method compared to shaping/clicker training. Applied Animal Behaviour Science, 171, 146-151.

Gerger, A. \& Rossi, A. 2011. Cão de familia: a arte de cuidar, educar e ser feliz com seu melhor amigo. Agir, Rio de Janeiro, Brasil.

Gruen, M. E. \& Sherman, B. L. 2008. Use of trazodone as an adjunctive agent in the treatment of canine anxiety disorders: 56 cases (1995-2007). Journal of the American Veterinary Medical Association, 233, 19021907.

Hannah, D. R. \& Robertson, K. 2017. HumanAnimal Work: A Massive, Understudied Domain of Human Activity. Journal of Management Inquiry, 26, 116-118.

Herzog, H. 2011. The impact of pets on human health and psychological well-being: fact, fiction, or hypothesis? Current Directions in Psychological Science, 20, 236-239.

Horowitz, A. 2010. A cabeça do cachorro: O que seu amigo mais leal vê, fareja, pensa e sente. Rio de Janeiro: Best Seller. Best Seller, Rio de Janeiro, Brasil.

Konecki, K. T. 2007. Pets of Konrad Lorenz. Theorizing in the social world of pet owners. Qualitative Sociology Review, 3.
Landsberg, G. M., Hunthausen, W. \& Ackerman, L. 2013. Is it behavioral, or is it medical. Behavior Problems of the Dog and Cat, 1, 7594.

Morgan, K. N. \& Tromborg, C. T. 2007. Sources of stress in captivity. Applied Animal Behaviour Science, 102, 262-302.

Raileanu, Y. A. \& Teixeira, C. M. C. 2015. Comparativo do comportamento social entre cães e humanos. Atas de Saúde AmbientalASA, 3, 48-63.

Rooney, N., Gaines, S. \& Hiby, E. 2009. A practitioner's guide to working dog welfare. Journal of Veterinary Behavior: Clinical Applications and Research, 4, 127-134.

Sargisson, R. J. 2014. Canine separation anxiety: strategies for treatment and management. depression, 10, 143-151.

Tatibana, L. S. \& Costa-Val, A. P. 2009. Relação homem-animal de companhia e o papel do médico veterinário. Revista Veterinária $e$ Zootecnia em Minas, 1, 12-19.

Thalmann, O., Shapiro, B., Cui, P., Schuenemann, V. J., Sawyer, S. K., Greenfield, D. L., Germonpré, M. B., Sablin, M. V., LópezGiráldez, F. \& Domingo-Roura, X. 2013. Complete mitochondrial genomes of ancient canids suggest a European origin of domestic dogs. Science, 342, 871-874.

Article History:

Received 20 November 2017

Accepted 08 January 2018

Available online 22 March 2018

License information: This is an open-access article distributed under the terms of the Creative Commons Attribution License 4.0, which permits unrestricted use, distribution, and reproduction in any medium, provided the original work is properly cited. 